\title{
OPERACIONALIZAÇÃO E DOCUMENTAÇÃO DO PROCESSO DE ENFERMAGEM EM UMA UNIDADE DE TERAPIA INTENSIVA NEONATAL
}

\author{
Camila Noronha Castilho*, Suellen Cristina Dias Emidio, Elenice Valentim Carmona.
}

\begin{abstract}
Resumo
Processo de Enfermagem é uma ferramenta importante para a assistência ao paciente, sendo uma forma de individualizar $o$ atendimento e realiza-lo de forma integral. Este processo dinâmico é dividido em fases interrelacionadas para organizar o raciocínio clínico do enfermeiro e auxiliar a abrangência do plano assistencial. Assim, esse estudo objetivou investigar os desafios enfrentados pelos enfermeiros na operacionalização e documentação do processo de enfermagem em uma unidade de terapia intensiva neonatal de um hospital público universitário. Estudo transversal e descritivo, no qual foi realizado auditoria de prontuários e aplicado um questionário aos enfermeiros. Os dados qualitativos foram avaliados em busca de subsídios para o planejamento de futura intervenção. Resultados: $O$ item que foi realizado com maior frequência foi a anotação de enfermagem ( $29=93,5 \%)$. Os diagnósticos reais estavam completos em $7(22,5 \%)$ dos 31 prontuários avaliados, enquanto os de risco em $20(64,5 \%)$. Quanto à motivação dos enfermeiros para realizar o PE, $8(47 \%)$, de um total de 17 , responderam que não se sentem motivados. Conclusão: O registro do PE necessita de aprimoramento, sendo o treinamento específico uma estratégia mencionada pelos próprios profissionais. Portanto o desenvolvimento desse estudo permitiu conhecer a realidade da Unidade, oferecendo subsídios para planejamento de estratégias que visem melhorar a operacionalização e documentação do PE.
\end{abstract}

\section{Palavras-chave}

Processos de enfermagem, Planos de cuidados de Enfermagem, Unidades de terapia intensiva neonatal.

\section{Introdução}

O Processo de Enfermagem (PE) é um instrumento que orienta $O$ cuidado individualizado, bem como a documentação da prática profissional'1. O PE fundamenta a assistência ao paciente, além de ser uma exigência legal. Assim, o presente estudo se justifica pela incompletude do PE na referida unidade, visto que a Evolução de Enfermagem não está implementada, sendo esta uma oportunidade preciosa de avaliação e registro dos resultados alcançados a partir da assistência oferecida. Esse estudo teve como objetivo investigar os desafios enfrentados pelos enfermeiros na operacionalização e documentação do Processo de Enfermagem em uma Unidade de Terapia Intensiva Neonatal.

\section{Método}

Tratou-se de um estudo transversal e descritivo, em que foi aplicado um instrumento para avaliar os registros de enfermagem dos prontuários da unidade em questão. Os enfermeiros responderam a um questionário com perguntas abertas e fechadas, a fim de verificar sua percepção sobre esse método de trabalho e os desafios que vivenciam em sua implementação. Os dados foram analisados com estatística descritiva.

\section{Resultados e Discussão}

Foram analisados 31 prontuários e contou-se com a participação de 17 enfermeiros que atuam na assistência direta ao recém-nascido. A anotação de enfermagem foi o item melhor realizado $(29=93,5 \%)$. A reavaliação do diagnóstico foi encontrada em apenas um $(3,2 \%)$ deles. Identificação dos profissionais e a checagem esteve entre os resultados ruins. De um total de 17 enfermeiros, apenas $4(23,5 \%)$ responderam corretamente as fases do PE. Não se sentem motivados para realizar o PE 8
(47\%) enfermeiros. A maioria $(14=82,3 \%)$ conhece outras classificações além da proposta pela NANDA-I, mas 4 (82,3\%) relatam que não fazem uso de classificações.

\section{Conclusões}

$O$ registro do $\mathrm{PE}$ necessita de aprimoramento. $\mathrm{O}$ treinamento específico foi mencionado pelos enfermeiros como uma necessidade da unidade. Assim, o desenvolvimento desse estudo subsidiará o planejamento de estratégias para melhorias, a fim de valorizar ainda mais o trabalho da enfermagem.

\section{Agradecimentos}

Agradeço a Universidade Estadual de Campinas (UNICAMP) que subsidiou financeiramente 0 desenvolvimento desse estudo, garantindo ótimas condições para sua realização e a equipe da unidade onde o estudo foi realizado por sua receptividade.

\footnotetext{
${ }^{1}$ COFEn - Conselho Federal de Enfermagem. Resolução n. 358, de 2009. Dispõe sobre a Sistematização da Assistência de Enfermagem e a implementação do Processo de Enfermagem em ambientes, públicos ou privados, em que ocorre o cuidado profissional de Enfermagem, e dá outras providências. Disponível em: http://novo.portalcofen.gov.br/resoluo-cofen3582009 4384.html.
} 